\title{
Muscle type temporomandibular disorders and orthodontics
}

\author{
H. Gil \\ Maxillofacial kinesiologist, Lecturer in the Dental Faculty of Montrouge, Université Paris Descartes
}

ABSTRACT

With painful temporomandibular disorders, the physiotherapist treatment makes it possible to treat the pains and dysfunctions of the masticatory apparatus. When these are diagnosed before orthodontic treatment, it is necessary to treat them so that they do not interfere with the dentofacial orthopaedics treatment. In this perspective, lingual rehabilitation according to the method "Fournier" is associated with Schultz Autogenic Training.

\section{KEYWORDS}

Tongue, temporomandibular disorders, training

\section{INTRODUCTION}

A significant portion of the population has temporomandibular disorder (TMD), but the percentage of patients seeking treatment is low compared to the prevalence of TMD (TMDs). Indeed, at least $50 \%$ of the general population would have at least one sign of TMD indicating a combined disc, muscle, and joint pathology ${ }^{2}$. Likewise, the population seeking treatment represents $3 \%-7 \%$ of the general population with a female-to-male ratio of $2: 1^{11}$. A more recent study ${ }^{5}$ refers to $4 \%-88 \%$ of the general population.

Despite the high prevalence of dysfunction, the need and demand for treatment remains low. For example, "the signs of $T M D$ cannot be considered pathological in all cases and therefore do not require systematic therapeutic management." 20 However, patients who eventually decide to consult for pain, joint noises, or dyskinesies are in many cases stuck in a kind of medical limbo being sent from doctor to doctor before they can find the specialist capable of diagnosing and proposing a therapeutic solution ${ }^{20}$.

It is often ENT physicians or general dentists who often receive the patient's concerns first. In the best-case scenario, the patient is referred to a odontologist who specializes in "occlusion disorders." Few of them are referred to a maxillofacial physiotherapist who can finally offer the patient a noninvasive and long-lasting solution. 
TMDs

TMD are multifactorial and complex pathologies. They can cause disorders characterized by pain and impaired manibular mobility. Depending on the evolution of etiological concepts, the management of TMDs has fluctuated.

In 1934, the first clinical signs were described ${ }^{4}$. During the golden age of the articulators and up to the 1980s, occlusion was perceived as the primary etiology of TMDs. The recommended treatment was to restore a "perfect" occlusion. This view continues to this day in the minds of some practitioners and patients, thus complicating therapeutic management. However, despite restoring their occlusal balance, some patients still experienced pain, mandibular functional discomfort, and/or decreased chewing strength. Since then, the concept of "occlusal whole" gave way to "neuromuscular theory27,24."

Thus, there was doubt over exclusively occlusal etiology and the introduction of the notion of muscular disharmony and stress in the onset of pain; the muscles that hold the mandibular position that is supposed to be "at rest" are overstretched. In 1992, psychosocial factors were incorporated into research diagnostic criteria for TMD (RDC/TMD).

Today, it is recognized that multifactorial etiopathy of TMD can combine occlusal, parafunction, postural imbalances, orofacial dyspraxia, and stress. Faced with this etiological heterogeneity, treatment cannot therefore be only local and mechanical, but must also be overall and behavioral. Treatment will aim to establish a balance by acquiring new masticatory and swallowing behavior consistent nasal breathing, realignment of spinal curvatures, stress management, and elimination of harmful habits.

The clinic highlights one common point for all patients with this pathology-i.e., a dysfunctional tongue and at least one parafunction such as centered, eccentric bruxism; sucking or biting of the lips, cheeks, tongue, fingers, objects; onychophagy; significant gum chewing; and nonphysiological mandibular movements. A uncoordinated tongue does not always lead to $T M D$, but they often go hand in hand with a tongue in a bad position.

The temporomandibular joint (TMJ) has the capacity of being highly adaptable. Patients with oromotor dyspraxia will not develop symptoms as long as balance is compensated by the physiological adaptation of the body. The precarious balance is threatened when the capacity for accommodation is exceeded. It can then be an expression of a malfunction of the masticatory apparatus. It should be noted that not all dyspraxic tongues need to be reeducated, but it should be done in a patient with TMD. A tongue that is not on the palate can create imbalances in the mouth, which can worsen existing negative bad habits and tics. They reflect a certain state of stress and deep tensions. 
Therapeutic management of TMD will combine lingual training with Schultz's autogenic training. The former makes it possible to achieve a biomechanical balance of oral function, and the latter is used to stop parafunctions.

\section{Diagnostic categories}

The diagnostic criterias for TMD (DC) TMD) were redefined in 2014. These entities, some of which may be combined, include 8 :

- Masticator myalgia (three subgroups: local myalgia, diffuse myofascial pain, and myofascial pain with referal);

- TMJ arthralgia;

- TMJ disc displacement (with reduction, with reduction with intermittent locking, without reduction with limited opening, without reduction without limited opening);

- TMJ degenerative disease;

- subluxation;

- secondary headaches attributed to TMD.

Regardless of diagnosis, the most common reason for consultation is pain, dysfunction (limiting mouth opening, difficulty chewing), and, incidentally, joint noises.

Based on the prevalence of TMD ${ }^{21}$, we can note that muscle pain is the most common diagnostic feature $(45.3 \%$ of the population represented), with other causes being disc luxations (36.2\%), arthralgia/arthritis/arthrosis (18.4\%), and asssociated symptoms (Table I).

Table 1

\begin{tabular}{|c|c|}
\hline \multicolumn{2}{|c|}{$\begin{array}{l}\text { Algias and/or dysfunctions of the mandibular system (ADMS) diagnosis and associated symptoms identified in a population } \\
\text { of } 300 \text { patients (from ROBIN \& CHIOMENTO, } 2011\end{array}$} \\
\hline $\begin{array}{l}\text { TMD diagnosis }(n=664) \\
\text { and associated symptoms }(n=110)\end{array}$ & $\begin{array}{l}\text { Number of patients } \\
(\% \text { calculated on } n=300)\end{array}$ \\
\hline $\begin{array}{l}\text { Muscular disorders: } \mathbf{n}=\mathbf{3 0 1}(\mathbf{4 5 . 3} \%) \\
\text { - Hypertrophy/tension of the masseters } \\
\text { - Myofascial pain (masseters) }\end{array}$ & $\begin{array}{l}187(62.3 \%) \\
114(38 \%)\end{array}$ \\
\hline $\begin{array}{l}\text { Disc luxation: } \mathbf{n}=\mathbf{2 4 1}(\mathbf{3 6 . 2} \%) \\
\text { - Reducible disc luxation } \\
\text { - Acute irreducible disc luxation }\end{array}$ & $\begin{array}{l}200(66.7 \%) \\
41(13.7 \%)\end{array}$ \\
\hline $\begin{array}{l}\text { Arthralgia, arthritis, arthrosis: } \mathbf{n}=122 \text { (18.4\%) } \\
\text { - Arthralgia (capsulitis / synovitis) } \\
\text { - Osteoarthritis } \\
\text { - Osteoarthrosis }\end{array}$ & $\begin{array}{l}89(29.6 \%) \\
8(2.6 \%) \\
5(1.7 \%) \\
\end{array}$ \\
\hline $\begin{array}{l}\text { Associated symptoms }(\mathbf{n}=\mathbf{1 1 0}) \\
\text { - Tension headaches/migraines } \\
\text { - Neck pain } \\
\text { - Tinnitus } \\
\text { - Dizziness } \\
\text { - Dental pains }\end{array}$ & $\begin{array}{c}43(14.3 \%) \\
41(13.7 \%) \\
19(6.3 \%) \\
5(1.7 \%) \\
2(0.7 \%)\end{array}$ \\
\hline
\end{tabular}




\section{GENERAL INFORMATION ON MAXILLOFACIAL TRAINING}

Fifty years ago, a new area of expertise was developed in physiotherapy: maxillofacial functional rehabilitation, which was more commonly attributed to speech therapists. Two physiotherapists were interested in the question. The same subject, the masticatory apparatus, but two different approaches and two different schools. The first ${ }^{19}$ aims at treating the consequence, above all by restoring correct mandibular kinetics. This work is based on the reprogramming of mandibular movements. The second school ${ }^{9}$, on the other hand, focuses its treatment on correcting the cause before treating the consequences. Thus, lingual training was born. This oromyofunctional education helps to establish a myofunctional balance and abolish harmful habits. Before starting lingual training, it is possible to offer the patient initial counseling and muscular relaxation exercises.

\section{EXERCISES TO BE PROPOSED AS FIRST INTENTION IN CASE OF MUSCLE PAIN}

In all of the exercises recommended below, it is essential to adhere to the painless and fatigability rule. No exercise is beneficial if it causes the slightest pain or discomfort, at the risk of provoking a nociceptive reaction that can result in reflex contracture. The patient must learn how to do the exercises for themselves, in order to control the intensity of their actions, and have a faster amelioration of their pain. The patient will be able to use these techniques as often as possible.

\section{Thermotherapy}

This is the first method to offer the patient in a lot of pain.

INDICATION: muscle pain and contractures (people with arthralgic pain are more tolerant of cryotherapy)

TECHNICAL: local application of heat to painful masseters

DURATION: approximately $20 \mathrm{~min}$; several times a day when necessary

PRINCIPLES: use of self-heating compresses or small packs of gels to be heated at proper temperature

\section{Endobuccal massage (Fig. 1)}

In most cases, the pain is of muscular origin and primarily involves deep masseters.

There are many physiological benefits of massage:

- On the vascular system, by allowing local hyperemia by vasodilation of the superficial blood vessels, which results in redness and warmth of the skin on the

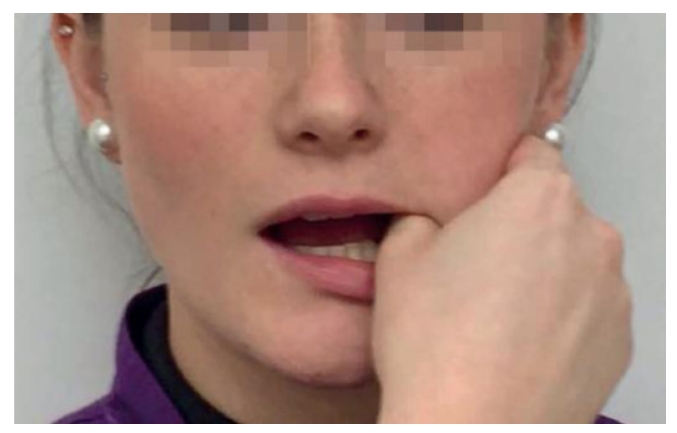

Figure 1 Endobuccal massage. 
massaged site. This phenomenon allows an increase in blood flow, thus increasing the supply of oxygen and nutrients, with the consequent acceleration of the elimination of toxins.

- $\quad$ On the lymphatic and immune system, by stimulating it. Indeed, lymph and lymphatic organs contribute to the protection of the body by filtering pathogens, abnormal cells, and foreign particles. These will then be released into the bloodstream.

- On the autonomic nervous system, by activating the the parasympathetic nervous system, with the subsequent decrease in heart rate, respiratory rate, improvement in digestive function, and increased muscle relaxation. In conjunction with this, there will be a decrease in the secretion of stress hormones (cortisol and adrenaline). Massage affects the secretion of endorphins in the brain. These hormones have an analgesic effect and provide a state of well-being.

- On the muscular system, by the analgesic action of massage; this is often recognized by patients but rarely yet proven in scientific and clinical studies.

The "Gate control" theory" ${ }^{16}$ has been mentioned many times. It states that massage would trigger stimuli through low-threshold, fast-conduction myelinated fibers. This results in presynaptic inhibition. The presynaptic gate closes, preventing the target cell from being reached and transmitting the painful message to the cortex.

This theory has been widely criticized $^{22}$ and the initial model has been modified, involving not one but two families of interneurons: one inhibiting and the other activating transmission neurons (T neurons) ${ }^{28}$.

INDICATION: muscle pain and contractures

TECHNICAL: The impact and analgesic effect are much greater when massaged is delivered tranversely through exobuccal and endobuccal routes. This involves placing the thumb (inside oral mucosa) and the index finger (outside of the cheek) on both sides of the masseter and sliding the fingers toward the labial commissure.

DURATION: approximately $5 \mathrm{~min}$; to be repeated several times per day

PRINCIPLES: This maneuver, like all physiotherapy exercises, it must be painless. Massage is the most effective when it can be repeated several times a day. That is why we should teach it to our patients. First, so that they can control their painful areas. Indeed, the physiotherapist can sometimes massage too hard and provoke a nociceptive reaction; the painful muscle will contract even more reflexively.

Second, the patient will be autonomous and able to use self-massage when they need it. This will help the masseters relax more quickly and efficiently.

\section{The "contracture release"}

The massage of the pterygoid muscles is frightfully excruciating and we are never certain we are truly on the muscle. The "contracture release" technique is more effective in relaxing them.

The contracture release technique is based on Sherrington's reciprocal 
inhibition principle ${ }^{26}$, which allows two motor responses. The first states that excitation of a motor neuron of a muscle (agonist) results in inhibition of the motor neuron of the antagonistic muscle (via an inhibitory interneuron located in the gray matter of the spinal cord, therefore, in the central nervous system). That is, it is not the antagonist muscle that is inhibited but its motor neuron (a muscle is either silent or excited but never inhibited). Secondly, this isometric muscle contraction will facilitate the activity of its agonists. Contracture release also optimizes immediate muscle relaxation after intense contraction. Indeed, we are witnessing a change in the viscous muscle stiffness after imposing a prior contraction effort ${ }^{12}$.

INDICATION: Muscle contractures, trismus resulting in amplitude limitations of mandibular kinematics. This exercise is contraindicated for joint pain.

TECHNICAL: There are five types of movement: oral closure, oral opening, mandibular propulsion, right and left side lateral movements.

- Oral closure (Fig. 2): Place hooked fingers on the lower dental arch to resist mandible rising.

- Oral opening (Fig. 3): Place your closed fists under the mandible to prevent it from being lowered.

- In mandibular propulsion (Fig. 4): Place fingers against chin; resist mandibular propulsion.

- Laterality (Fig. 5 and 6): Place closed fists on each side of the mandible, opposing the lateral movement of the mandible.

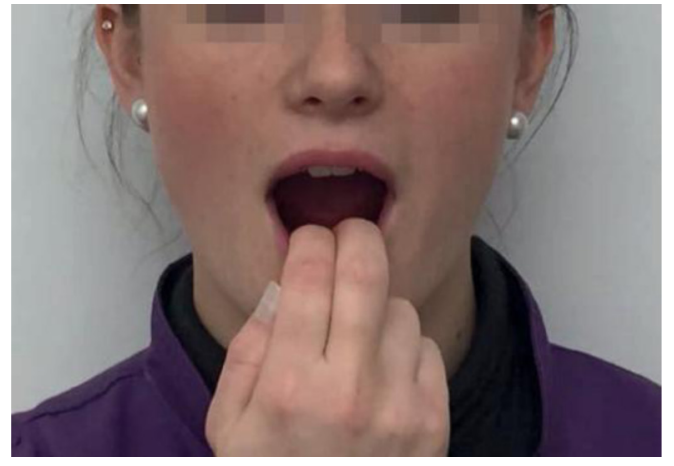

Figure 2

Contracture release in oral closure.

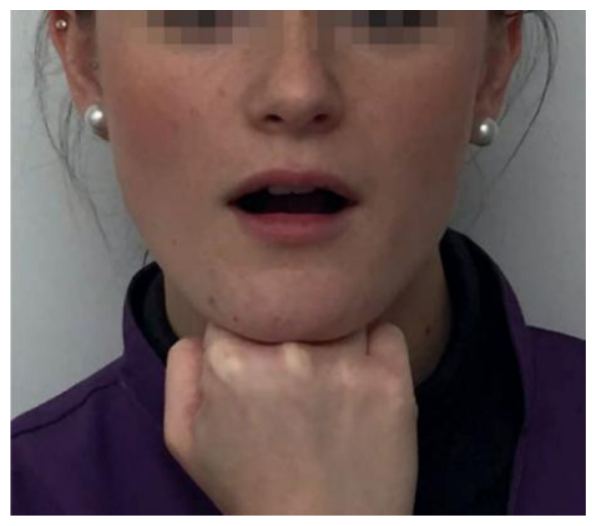

Figure 3

Contracture release oral opening.

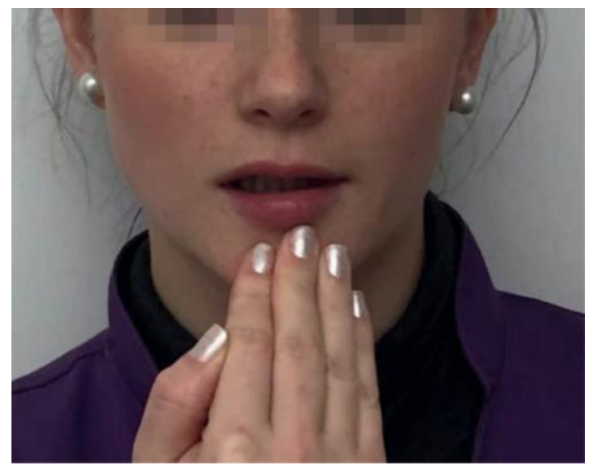

Figure 4

Contracture release in mandibular propulsion. 

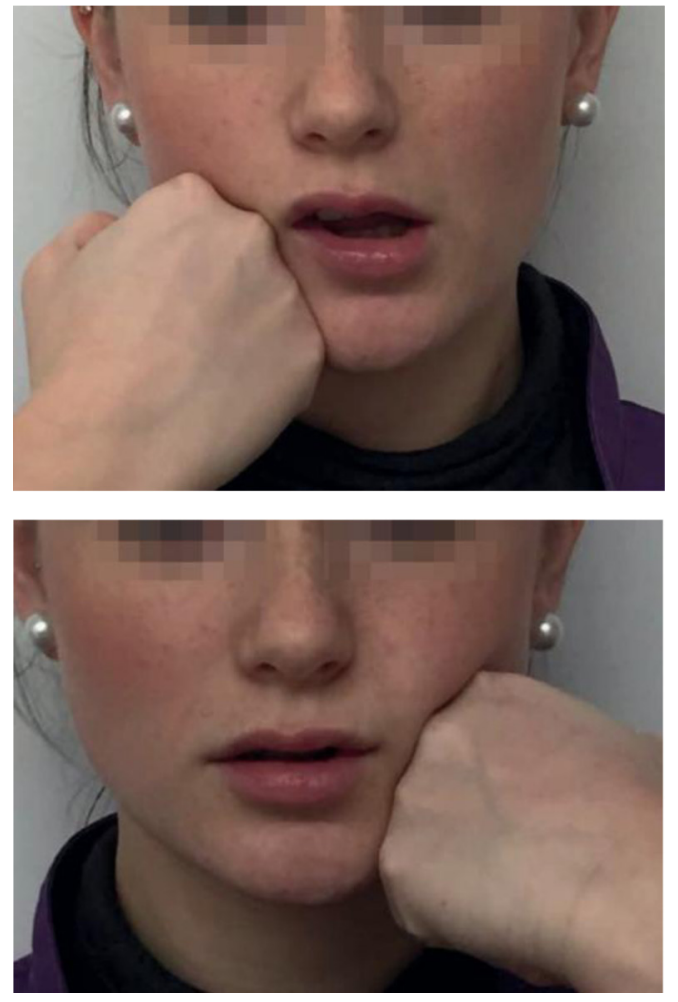

Figure 5 and 6

Contracture release in right and left lateralities.
DURATION: 3 s at one time, five times in a row; but repeat several times a day if necessary

PRINCIPLES: This is a purely isometric movement, without displacement against significant resistance. All movements must be made exclusively without occlusal contact. The goal is the release of muscle tension and joint stiffness. This exercise is mostly effective on trismus and oral opening limitations.

If the pain is too severe, it is then more appropriate to suspend this exercise for a while, and use heat application and massage instead. At the point when the patient is less painful, the contracture release can be repeated for 1 second and in a very small range of oral opening. Progression will be achieved by increasing the contraction time and the amplitude of oral opening.

\section{LINGUISTIC TRAINING ACCORDING TO THE METHOD PROVIDED}

This therapy consists of fixing incorrect linguistic postures and praxis according to tryptic ${ }^{3}$ : at rest, swallowing, and phonation. At the same time, it is necessary to achieve a balance between the agonist and antagonist muscles and nasal ventilation during wakefulness, sleep, rest, and exertion. Posture disorders are managed while parafunctions can be eliminated through the practice of Schultz relaxation.

\section{Interest}

TMD can be perpetuated by lingual malposition and the presence of bad habits and tics. It is essential to correct the poor lingual posture, to restore the functions that integrate a tongue into the palate and, above all, to intervene on the behavioral factors through "stress management." 
The Fournier method incorporates the fact that the patient must acquire the tools that will enable them to manage their deep tensions. The patient must be able to identify them on their own before they become permanent and thus avoid chronic transformation of the pain. This is the only way to achieve sustainable results.

The patient is the main actor in their treatment. With this in mind, all exercises must be learned and practiced daily, until the pain is gone and the correct motor pattern is acquired at the orofacial sphere. As long as the ingrained corrections are not obtained, it is necessary to continue with the same sessions.

The uniqueness and difficulty of this method lies in the fact that the physiotherapist is essentially there to teach exercises and to support the patient in their care process. The patient needs to understand that if they want to get better and feel good over time, they need to change their behavior patterns and accept the "letting go" of their parafunctions.

\section{Reminders (Chateau's Tryptic)}

\section{Lingual posture at rest (Fig. 7)}

The apex, the tip of the tongue, is in contact with the retroincisive papillae on

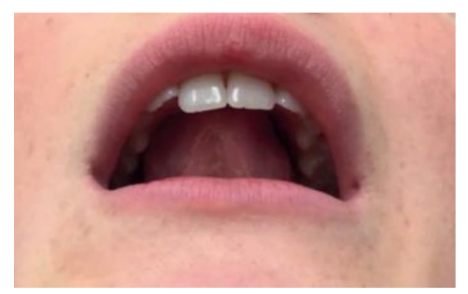

Figure 7

Lingual posture at rest. the palate. "Contact" implies touching, even facing, but especially not in force. The edges of the tongue have no indentations and are at the level of alveolar processes. The tongue should have a dome form.

\section{Swallowing}

Normal swallowing is accomplished by the apex pressing hard on the retroincisive papillae, unlike the resting position where the tongue barely touches, with interdental contact and without any involvement of the labiojugal muscle band, starting at 3 years.

\section{Phonation}

In normal phonation, LNDT palatals should be apex on retroincisive papillae. When the patient suffers from oromotor dyspraxia, palatal sounds can become dental sounds. As their name indicates, the tongue will then project onto the teeth.

\section{Linguistic rehabilitation}

The first-line exercises described above can provide quick relief, but are often insufficient to permanently resolve TMD. Therefore, it is advisable to explain to the patient that a lingual dyspraxia appears to be a maintenance factor for TMD. When symptoms persist, tongue movement training should be provided. This will only be effective if it is accompanied by Schultz's relaxation.

It should be noted that scientific evidence of the effectiveness of different physical therapies is weak, limited, and has little long-term impact ${ }^{17}$. On the other hand, they seem to bring genuine relief in the short term. 


\section{To who should the patient be referred to?}

In order to be able to intervene on TMD on a long-term basis, it is preferable to refer the patient to a therapist capable of managing lingual dyspraxia

\section{MANAGING TENSIONS IN TMDS}

\section{The "lingual trilogy"}

The concept of stress in TMD is no longer discussed ${ }^{25,14}$. This has made it possible to take a psychophysiological approach to TMD and no longer just mechanical and occlusal.

A model ${ }^{18}$ is representative of what we tell our patients. Orthlieb evokes a triad: Predisposing factors/Triggering factors/Maintenance factors. According to this author, in taking a medical history we find:

- Predisposing factors (maximum interscuspal position disorder, postural abnormalities, tension, stress, depression, parafunctions, which would deccrease the resistance threshold of the mandibular system);

- Triggering factors (alteration of occlusal relationships following implant installation, wisdom tooth extraction, uncompensated tooth extraction, long-term dental care, poorly balanced bridge, orthodontic treatment or masticatory apparatus trauma, and psychological shock that can lead to increased stress); while working on the behavioral aspect. It should be noted that not all physiotherapists trained in the Fournier method are trained in Schultz relaxation. If this is not the case, patients may be referred to a sophrologist or hypnotherapist in addition to tongue training.

- Maintenance factors (lingual dyspraxia, tension, stress).

In view of this, it would be inconceivable not to deal with the deep tension and stress, which are not only predisposing factors but also triggering factors and especially all factors that contribute to the maintenance these disorders.

\section{Behavioral approach}

Generally, patients expect "classic" training combining massages, mandibular mobility exercises, etc. They often have great difficulty perceiving the relationship between the behavioral aspect and the onset of their symptoms. To change the behavioral character, and thus to act on the stress and tension factors, it is preferable to minimize the occlusal aspect and introduce the notion of "demystification of the disease" 6 .

The link between TMD and occlusion has not been proven. An imperfect occlusion does not automatically result in TMD, despite the presence of triggering factors. Because the adaptative capacity of the masticatory apparatus 
is not the same in all individuals and differs according to the periods of life $^{10}$, some patients will develop TMD at some point in their lives, and others will not. Likewise, there may be perfect occlusions with TMD. However, there is no doubt that those who combine lingual dyspraxia, fluctuating psychological state, tension, and stress will be more likely to develop TMD at some point than others.

\section{Bad habits and tics}

Bad habits are acts that a subject undertakes on their body, whose deep origin is instinctive; but this aspect is masked by a character of irresistibility and insatiability ${ }^{1}$. Tics are unconscious acts represented by repetitive movements from time to time, beyond the control of the will. This could be likened to a reaction that persists even after the original excitement that gave rise to it has disappeared, such as the remaining linguistic impulse (called the "tongue stage"), that may be caused by an overly peremptory or too early stoppage of the thumb sucking. It seems that the tic is accomplished by itself, apart from the participation of the conscience, often even against the patient's will.

Despite their different origins and characteristic mode of expression, one thing that combines the bad habits and tics, the tense state they convey, the pleasure, and the relaxation they provide when they are performed. The study of cognitive and affective neurosciences provides a better understanding of the origin of parafunctions and the difficulty stopping them ${ }^{15}$. Indeed, these archaic tics appear to be the responsibility of the reptilian brain, which is responsible for basic needs (thirst, hunger, sleep, sexual impulses), defensive reflexes (flight, aggression) and not the neocortex, the seat of cognition. Asking a patient to stop licking or biting their lips is very difficult. The tic surpressed by an external constraint can cause anxiety, as can the repressed bad habit.

\section{Changing behavior}

Several authors ${ }^{9,17}$ refer to the "self-management" of dysfunction. Breaking the vicious circle of pain and contracture cannot be done without eliminating parafunctions, easing muscle tension, decompressing the joint, and relieving pain. Patients must act according to their symptoms ${ }^{13}$. Pain and dysfunction must no longer be suffereed, but accepted and dealt with. Chronic pain and psychosocial stress are intimately related ${ }^{17}$. Psychological difficulties would act as a "catalyst" for $\mathrm{TMD}^{10}$. The masticatory apparatus would be a preferred area for somatization of psychological disorders.

Strictly reeducating TMD mechanically is not enough and does not protect against the risk of reoccurence. A more psychological approach to TMD is essential, in the sense that the patient must learn to let go if they wants to deal with their stress and tensions, and therefore their dysfunction.

In summary, effective long-term maxillofacial training involves technical exercises for the mechanical aspects, but above all, stress management. In order to manage these patients, often described as "difficult," it is necessary to be able to hear their pain, their suffering, to lead them to change their way of doing things, and perhaps in some way, to change their way of being. 


\section{SCHULTZ' AUTOGENOUS TRAINING ${ }^{23}$}

It is the most effective technique for dealing with deep tensions. It is a method of relaxation, which involves putting oneself in a modified state of consciousness, close to deep sleep. The patient must acquire the skill in order to practice this alone. This autonomy is essential in order to obtain deep relaxation and thus a therapeutic effect. The patient will develop a genuine "conditioning" that will allow them to relax their tensions when and where they want. Schultz's relaxation acts on neurovegetative hyperactivity, and therefore on stress, tension, and fatigue.

\section{CONCLUSION}

In TMD management, it is essential to make the patient be aware of the need to change their behavior pattern. Their mouth pain and discomfort is not just a reductive or nonreductive disc luxation, or an occlusal balance that has been altered. They are mainly caused or perpetuated by lingual dyspraxia and by the presence of bad habits and tics that will have to be corrected.
Combining TMD treatment with relaxation is the first therapeutic approach to avoid the risk of reappearance of pain and dysfunction.

Only this combination gives the patient the means to manage their deep tension.

Conflict of interest: The authors declare no conflicts of interest.

\section{REFERENCES}

1. Bonaparte M. Des autoérotismes agressifs par la Griffe et par la Dent. La Revue française de psychanalyse, Paris 1933;4(2):192-216.

2. Bonjardim LR, Lopes-Filho RJ, Amado G, Albuquerque RL, Jr, Goncalves SR. Association between symptoms of temporomandibular disorders and gender, morphological occlusion, and psychological factors in a group of university students. Indian J Dent Res 2009;20:190-194.

3. Chateau M. Orthopédie dento-faciale, tome 2, Clinique. Paris : Éditions CdP,1993:25-26.

4. Costen D. Syndrome of ear and sinus symptoms dependent upon disturbed function of the TMJ. Am Otol Rhinol Laryngol 1934;43:1-15.

5. Descroix V. Douleurs orofaciales. Édition CdP, Arnette, 2013.

6. Dupas P. Nouvelle approche du dysfonctionnement crâniomandibulaire. Du diagnostic à la gouttière. Paris : CdP,2005, $203 p$.

7. Dworkin SF, LeResche L. Research diagnostic criteria for temporomandibular disorders: review, criteria, examinations and specifications, critique. J Craniomandib Disord 1992;6(4):301-55.

8. Fougeront N. Examen clinique fonctionnel de I'appareil manducateur. In : Saulue P, Palla S, Michelotti A, Laluque JF (éditeurs). « Assymétrie et fonction » 2017. Paris: Quintessence, p. 131-144. 
9. Fournier M, Chauvois A, Girardin F. Rééducation des fonctions dans la thérapeutique orthodontique. Éditions SID, 1991:229.

10. Gola R, Chossegros C, Orthlieb JD. Thérapeutiques adjuvantes. Chapitre 15. In : Syndrome algo-dysfonctionnel de l'appareil manducateur, 2e édition. Paris : Masson, 1995:213-220.

11. Gonzalez YM. Are temporomandibular disorders a public health problem? Alpha Omegan 2003;96(2):11-14.

12. Gottlieb GL, Agarwal GC. Modulation of postural reflexes by voluntary movement. J Neurol Neurosurg Psychiatry 1973;36(4):529-539.

13. Green CS. The etiology of temporomandibular disorders; implication for treatment. J Orofac Pain 2001;15:93-105.

14. Le Gall MG, Lauret JF. Occlusion et fonction. Une approche clinique rationnelle. Paris : CdP,2002, $171 \mathrm{p}$.

15. Maclean P. A Tribune Concept of the Brain and Behavior. In : T. Borg, D. Campbell (éd.). The Hinks Memorial Lectures. Toronto: University of Toronto Press, 1973, p. 9-10.

16. Melzack R, Wall PD. Pain mechanisms: a new theory. Science 1965;150:971-979.

17. Michelotti A, lodice G, Vollaro S, Steenks MH, Farella M. Evaluation of the short-term effectiveness of education versus an occlusal splint for the treatment of myofascial pain of the jaw muscles. $J$ Am Dent Assoc 2012;143(1):47-53.

18. Orthlieb JD. La fonction occlusale et ses dysfonctionnements. Réalités cliniques : revue européenne d'odontologie 1996;7(2):131-143.

19. Psaume Vandebeek D. Éditions CDP (entretien Clinic n 2 du 1.2.2017 par Anne Chantal de Divonne).

20. Robin O, Carpentier P. Données actuelles sur le traitement des algies et dysfonctionnements de I'appareil manducateur. Journées pratiques d'odontologie 22 et 23 juin 2006, Lyon. Chir Dent Fr 2006;1234/1264:29-41.

21. Robin O, Chiomento A. In : Robin O. "Algies et dys- fonctionnement de l'appareil manducateur ». Paris : EDP Sciences, 2011.

22. Ropero Pelaez FJ, Taniguchi S. The Gate Theory of Pain Revisited: Modeling Different Pain Conditions with a Parsimonious Neurocomputational Model. Neural Plast 2016;4131395.

23. Schultz JH. Le training autogène. Paris : PUF, 1974.

24. Schwartz LL. A temporomandibular joint pain-dysfunction syndrome. J Chronic Dis 1956;3(3): 284-293.

25. Selye H. Thymus, Adrenals in the Response of the Organism to Injuries and Intoxications. Br J Exp Pathol 1936;17(3):234-248.

26. Sherrington C, Molnár Z, Brown RE. Insights into the life and work of Sir Charles Sherrington. Nat Rev Neurosci 2010;11:429-436.

27. Travell JG, Simons DG. Myofascial pain and dysfunction, the trigger point manual. Baltimore: Williams and Wilkins, 1983.

28. Wall PD. The gate control theory of pain mechanisms: a re-examination and re-statement. Brain 1978;101:1-18. 